\title{
Efecto del zinc sobre la inducción de ramas productivas en gulupa (Passiflora edulis Sims)
}

\section{Effect of zinc on the induction of productive branches in the purple passion fruit (Passiflora edulis Sims)}

ARLETTE IVONNE GIL C..$^{1,3}$

MIGUEL MARROQUÍN M. ${ }^{2}$

LUCILA MARTÍNEZ C. ${ }^{2}$

Brotación de nuevas ramas en gulupa.

Foto: F.A. Gil C.

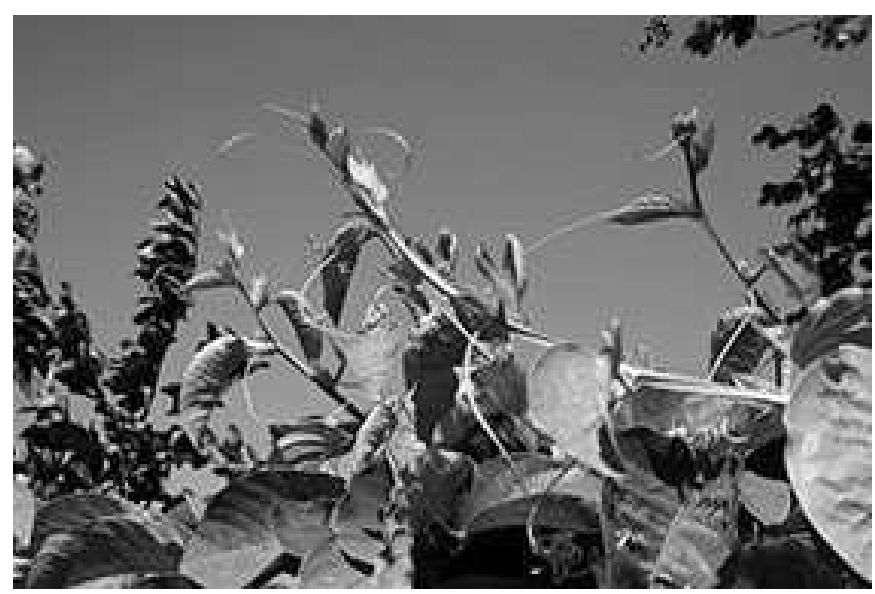

\section{RESUMEN}

En la región del Sumapaz (Cundinamarca) el cultivo de gulupa o maracuyá morado (Passiflora edulis Sims) presenta disminución en floración y fructificación después del primer ciclo de cosecha, afectando la producción. Una alternativa consiste en implementar prácticas agronómicas para elevar la eficacia en cada uno de los ciclos. Se evaluó el método de aplicación y dosis de dos fertilizantes que contienen zinc ( $\mathrm{Zn}$ ) sobre las ramas productivas, debido a su intervención en la formación de auxinas mediante activación enzimática en la síntesis de triptófano, precursor del ácido indolacético (AIA). El experimento se llevó a cabo en el municipio de Granada (Cundinamarca), con plantas de 18 meses, en un diseño en bloques completamente al azar con tres repeticiones y cinco tratamientos: quelato de $\mathrm{Zn}(10 \%)$ en dosis de 3,6 y $9 \mathrm{~kg} \mathrm{ha}^{-1} \mathrm{de} \mathrm{Zn}$ aplicados foliarmente cada 15 días con un total de ocho aplicaciones, sulfato de Zn (28\%) en forma edáfica en dosis de $6 \mathrm{~kg} \mathrm{ha}^{-1} \mathrm{de}$ $\mathrm{Zn}$ en dos aplicaciones cada mes, y un testigo absoluto. Se tomaron datos cada 15 días sobre longitud de ramas productivas y número de brotes productivos. Para longitud de ramas se obtuvo diferencia significativa a partir de los 45 días, siendo las aplicaciones foliares las de mejores resultados. Para número de brotes no se obtuvo diferencia entre tratamientos ya que el aumento en las ramas productivas se vio reflejado en elongación y aumento en la distancia entrenudos. Los mejores resultados se obtuvieron aplicando quelato de zinc en forma foliar en dosis de $3 \mathrm{~kg} \mathrm{ha}^{-1}$.

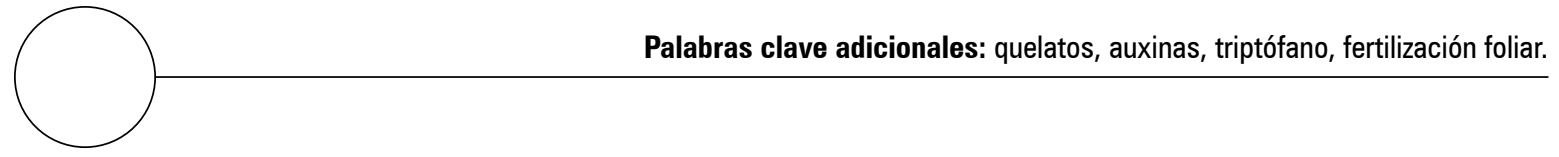

\footnotetext{
Programa de Ingeniería Agronómica, Grupo de investigación PROSAFIS, Universidad de Cundinamarca, Fusagasugá (Colombia).

2 Programa de Ingeniería Agronómica, Universidad de Cundinamarca, Fusagasugá (Colombia).

3 Autor para correspondencia. arlettegil@hotmail.com
} 


\section{ABSTRACT}

In the region of Sumapaz (Cundinamarca), the culture of the purple passion fruit (Passiflora edulis Sims) presents diminution in flowering and fructification after the first harvest cycle, affecting production. An alternative consists of implementing agronomical practices to increase the effectiveness in each of the cycles. We evaluated the method of application and doses of two fertilizers that contain zinc $(\mathrm{Zn})$ with productive branches, due to its intervention in the formation of auxins by enzymatic activation in the synthesis of tryptophan, the precursor of indoleacetic acid (IAA). The experiment was carried out in the municipality of Granada (Cundinamarca), with 18-month-old plants, with a design of randomized complete blocks with three repetitions and five treatments: chelated zinc (10\%) at doses of 3, 6 and $9 \mathrm{~kg} \mathrm{ha}^{-1}$ of $\mathrm{Zn}$ applied in a foliar form every 15 days with a total of eight applications; zinc sulfate (28\%) in an edaphic form with a dose of $6 \mathrm{~kg} \mathrm{ha}^{-1}$ of $\mathrm{Zn}$ with two applications every month; and one control treatment. Every 15 days, data for the length of the productive branches and number of productive buds were taken. For length of branches, statistical differences from 45 days were obtained, with the foliar applications having the better results. For number of buds, statistical differences between treatments were not obtained due to the fact that increases in productive branches were reflected in elongation and increase in the internode distance. The best results were obtained by applying chelated zinc in a foliar form, at a dose of $3 \mathrm{~kg} \mathrm{ha}^{-1}$ of $\mathrm{Zn}$.

Additional key words: chelates, auxins, tryptophan, foliar fertilization.

Fecha de recepción: 24-08-2012

Aprobado para publicación: 28-11-2012

INTRODUCCIÓN

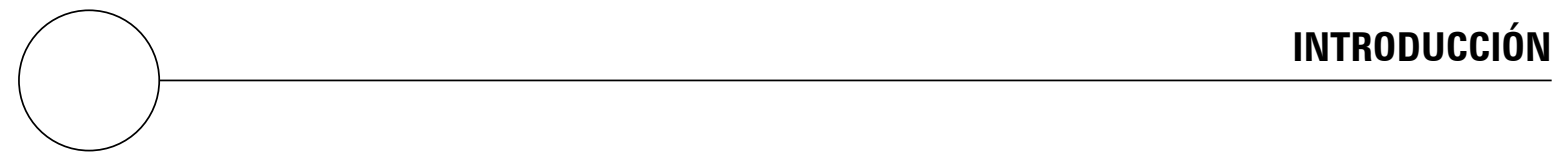

Los productos exóticos colombianos se encuentran dentro de las nuevas preferencias por novedosos, convenientes, inocuos y con altas calidades nutricionales, pero el desempeño de los frutales promisorios ha sido lento, difícil y muy fluctuante, con bajos volúmenes y poca continuidad, insuficiente para posicionar al país y lograr el desarrollo de una verdadera diversificación exportadora del sector frutícola. La gulupa (Passiflora edulis Sims) es considerada un fruto exótico, que puede ser consumido en fresco o procesado, pero su inserción en los mercados internacionales al igual que otros productos de su condición presenta obstáculos debido a que no se cuenta con una oferta permanente y significativa, lo que se traduce en volúmenes exportados menores a los que potencialmente pueden ser demandados y precios más altos que los de otros productos similares (Espinel et al., 2005).
Esta problemática se ve reflejada en los cultivos de gulupa de la región del Sumapaz en donde se presenta un decrecimiento en la producción representada por la disminución de la floración y fructificación después del primer ciclo de cosecha. Una alternativa para mitigar este problema consiste en la implementación de prácticas agronómicas adecuadas que permitan elevar la eficacia en cada uno de los ciclos de cosecha. De este modo, el uso adecuado de un programa de fertilización permite suplir a la planta de los elementos necesarios para favorecer el normal desarrollo de las actividades fisiológicas de la planta.

La gulupa es también conocida como maracuyá morado, pertenece a la familia Passifloraceae y es originaria del sur de Brasil. Fue ampliamente distribuida durante el siglo XIX a América del Sur, el Caribe, Asia, África, India y Australia (Naka- 
sone y Paull, 1998). De acuerdo con Wenkam (1990) los frutos son ampliamente valorados por su sabor, aroma y contenido nutricional como fuente de provitamina A, niacina, riboflavina y ácido ascórbico. El fruto maduro de la gulupa es de color púrpura oscuro, redondeado u ovalado, de aproximadamente cinco centímetros de longitud, con un peso de 30 a $45 \mathrm{~g}$, con numerosas semillas negras envueltas en un saco de color naranja (Knight y Sauls, 2005).

En Colombia, las pasifloráceas cultivadas requieren diferentes rangos de temperatura para su óptimo crecimiento, desarrollo y producción. Para gulupa se encuentra entre 15 y $20^{\circ} \mathrm{C}$. Temperaturas más altas deshidratan el líquido estigmático imposibilitando la fecundación de las flores. El rango óptimo para la polinización está entre 25 y $30^{\circ} \mathrm{C}$. La alta radiación solar aumenta el potencial de rendimiento, la coloración y los grados Brix del fruto, pero induce el riesgo de "golpe de sol". La altitud recomendada para el cultivo está entre 1.400 a $2.200 \mathrm{msnm}$ (Fischer et al., 2009).

La esencialidad del zinc ( $\mathrm{Zn}$ ) en plantas fue demostrada inicialmente en maíz y posteriormente en cebada y girasol enano. Los primeros reportes de síntomas de deficiencias severas de zinc incluyen elongación defectuosa de ramas en tomate (Sekimoto et al., 1997). Dicha deficiencia incluye reducida síntesis de proteína y almidón mientras que el contenido de azúcar no se ve afectado. La actividad de algunas enzimas respiratorias, la acumulación de quinonas y cambios en los niveles de proteínas y aminoácidos han sido reportados en deficiencia de $\mathrm{Zn}$ (Klein et al., 1962). En la mayoría de cultivos, la concentración foliar típica de zinc requerida para un adecuado crecimiento está entre 15 a $20 \mathrm{mg} \mathrm{kg}^{-1}$ de materia seca (Broadley et al., 2007).

El zinc no forma parte de ningún componente estructural pero sí de varias enzimas como la anhidrasa carbónica, deshidrogenasa láctica, deshidrogenasa alcohólica, aldolasa, deshidrogenasa glutámica, carboxilasa pirúvica y ribonucleasas
(Ríos y Corella, 1999). Este metal es un constituyente de numerosas enzimas como anhidrasas, oxidasas y peroxidasas y desempeña un papel importante en regular el metabolismo del nitrógeno, la multiplicación celular, la fotosíntesis y la síntesis de auxinas (Rout y Das, 2003). Una de las funciones importantes del zinc es la regulación de la expresión de genes al formar parte de factores de transcripción de los cuales varias proteínas han sido implicadas en la regulación de procesos biológicos como desarrollo de la flor, morfogénesis regulada por la luz y respuestas a patógenos (Takatsuji, 1998).

El zinc es un elemento menor que activa la enzima triptófano sintetasa, encargada de la síntesis del triptófano para la biosíntesis del ácido indolacético (AIA), expansión foliar y crecimiento de brotes en zonas meristemáticas. En deficiencia de zinc la síntesis de auxina queda reducida al no sintetizarse el triptófano, que requiere la actuación de la enzima activada por el zinc, la cual une la serina y el anillo indólico (Gil, 1995). A pesar de ello, el modo de acción del zinc sobre el metabolismo auxínico aún es desconocido (Hanafy-Ahmed et al., 2012).

Este elemento es absorbido por la planta como quelato por vía radical o foliar. En el transporte a larga distancia (xilema) está ligado a los ácidos orgánicos o como catión divalente libre. En la savia floemática se presenta en concentraciones muy altas en donde probablemente se encuentra ligado a solutos orgánicos de bajo peso molecular. Podría estar unido a fosfolípidos y grupos sulfhidrilos protegiendo a los lípidos y proteínas de membrana contra el daño oxidativo (Marschner, 2002). Los bajos niveles de AIA en plantas deficientes en $Z n$, resultan de la degradación oxidativa de las enzimas superóxido-dismutasa (SOD) y catalasa, disminuyendo su actividad (Cakmak y Marschner, 1988).

También se encuentra en la isoenzima CuZnsuperoxidodismutasa (CuZnSOD) asociada con cobre donde el átomo de cobre representa el 
componente catalítico metálico y el zinc, estructural. Esta desempeña un importante papel en la degradación de radicales superóxido. Los síntomas visuales característicos de deficiencia del elemento en plantas son internodos cortos y disminución de la expansión foliar, relacionado con disturbancias en el metabolismo del AIA (Ratto et al., 1991; Kirkby y Römheld, 2007).

El transporte del zinc desde las células epidermales y corticales hacia el xilema de la raíz puede ocurrir vía simplástica, desde donde el zinc es bombeado hacia el apoplasto de la estela (Lasat y Kochian, 2000). Esta vía es catalizada por la membrana plasmática y la actividad del trasporte en el tonoplasto. El zinc puede también ser liberado extracelularmente al apoplasto de la estela en regiones donde la banda de Caspary no está completamente formada (White, 2001). Los flujos apoplásticos son dominados por la capacidad de intercambio catiónico de la pared celular, la formación de la banda de Caspary y los flujos hídricos (Sattelmacher, 2001).

La dinámica del zinc en el suelo es similar al cobre o hierro, donde a pH menor de 5 es más disponible, pero las pérdidas por lixiviación aumentan al incrementar su solubilidad. Se encuentra disponible en el suelo a $\mathrm{pH}$ de 5 a 6 . A pH más alto forma compuestos poco solubles (Marschner, 2002). En suelos alcalinos tiene una movilidad limitada debido a que el carbonato de calcio reacciona con el zinc, lo que reduce su disponibilidad (Fassbender y Bornemisza, 1987).

La deficiencia de zinc está muy difundida en sistemas productivos a nivel mundial. Se considera que el mejor diagnóstico de la condición se logra de la combinación de la observación de síntomas con el análisis foliar y el análisis de suelo (Sekimoto et al., 1997). La extracción de zinc del suelo luego de cada cosecha se traduce en valores de $\mathrm{Zn}$ soluble e intercambiable muy bajos al finalizar el ciclo y el sistema queda empobrecido para el cultivo siguiente. Esto produce un desplazamiento del equilibrio del $\mathrm{Zn}$ en el sistema, la fracción disponible para la planta es menor a la de extracción por el cultivo y se manifiesta la deficiencia (Ratto y Miguez, 2006).

Recientemente se han descubierto dos genes interruptores que regulan la absorción de zinc en Arabidopsis thaliana: bZIP19 y bZIP23, que si dejan de funcionar simultáneamente, la planta se vuelve hipersensible a la falta del elemento. Se debería encontrar el mecanismo para activar estos genes de forma que las plantas puedan absorber más zinc y además que sirvan para limpiar suelos contaminados con el elemento (Sikkema, 2010).

Para observar el efecto de la fertilización de zinc sobre la planta de gulupa, se evaluaron diferentes dosis, modos de aplicación y fuentes del elemento sobre la longitud de ramas productivas y número de brotes productivos con el fin de encontrar resultados que puedan promover una producción continua después del primer ciclo de cosecha.

\section{MATERIALES Y MÉTODOS}

Esta investigación se llevó a cabo en un cultivo de gulupa de 18 meses después de establecido en la finca El Progreso, vereda Guayuribe, municipio de Granada (Cundinamarca), ubicada geográficamente entre los $4^{\circ} 31^{\prime} \mathrm{N}$ y $74^{\circ} 22^{\prime} \mathrm{W}$, a una altitud de $2.200 \mathrm{msnm}$, temperatura promedia de $17^{\circ} \mathrm{C}$, humedad relativa promedia de $80 \%$ y precipitación promedia anual de 2.000 $\mathrm{mm}$.

Se empleó un diseño de bloques completamente al azar (BCA) con cinco tratamientos y tres repeticiones, para un total de 15 unidades experimentales (tabla 1). De acuerdo con los resultados del análisis de suelos de la parcela, cuya textura fue franco arenosa (56\% arena; 32\% limo; $12 \%$ arcilla), con un pH de 5,25 (fuertemente ácido), contenido de zinc de $4,7 \mathrm{mg} \mathrm{kg}^{-1}$ (alto), y los requerimientos nutricionales de zinc para gulupa 


\section{Tabla 1. Tratamientos establecidos en la investigación de aplicación de Zn sobre la inducción de ramas productivas en gulupa (Passiflora edulis Sims) en Granada, Cundinamarca.}

\begin{tabular}{|l|l|l|}
\hline \multicolumn{1}{|l|}{ Tratamiento } & $\begin{array}{c}\text { Método de } \\
\text { aplicación }\end{array}$ & Dosis de Zn \\
\hline Testigo & Ninguno & $0 \mathrm{~kg} \mathrm{ha}^{-1}$ \\
\hline Quelato de $\mathrm{Zn}$ & Foliar & $3 \mathrm{~kg} \mathrm{ha}^{-1}$ \\
\hline Quelato de $\mathrm{Zn}$ & Foliar & $6 \mathrm{~kg} \mathrm{ha}^{-1}$ \\
\hline Quelato de $\mathrm{Zn}$ & Foliar & $9 \mathrm{~kg} \mathrm{ha}^{-1}$ \\
\hline Sulfato de Zn & Edáfico & $6 \mathrm{~kg} \mathrm{ha}^{-1}$ \\
\hline
\end{tabular}

(de 45 a $80 \mathrm{mg} \mathrm{kg}^{-1}$ ), se realizaron los cálculos respectivos para fertilizar las plantas. Las fuentes utilizadas fueron quelato de $\mathrm{Zn}(10 \%)$ y sulfato de $\mathrm{Zn}(28 \%)$ en forma foliar y edáfica respectivamente. Las aplicaciones para el tratamiento foliar se realizaron con una frecuencia quincenal durante 105 d (ocho aplicaciones). Para la aplicación edáfica se realizaron fertilizaciones cada 30 d, fraccionando la aplicación total $(6 \mathrm{~kg})$ en dos aplicaciones.

Las variables evaluadas fueron: longitud de ramas productivas y número de brotes productivos. La frecuencia de muestreo fue quincenal, tomando tres ramas por planta y tres ramas por repetición. El análisis estadístico de los datos obtenidos se realizó en SAS/STAT versión 9.0 para análisis de varianza y prueba de comparación múltiple de Tukey.

\section{RESULTADOS Y DISCUSIÓN}

\section{Longitud de ramas productivas}

De acuerdo con los resultados obtenidos, se observó que hasta los 30 d después de la aplicación de $Z n$ no se presentaron diferencias estadísticas, sin embargo, sí las hubo a partir de los $45 \mathrm{~d}$ de la aplicación. Cuando se realizó la prueba de Tukey, se pudo establecer que los tratamientos que consistieron en aplicación de $\mathrm{Zn}$ en forma foliar a partir de la fuente como quelato, superaron al testigo y a la aplicación edáfica con sulfato de Zn a partir de los 45 d de la aplicación, como se observa en la tabla 2.

Lo anterior indica que la aplicación del zinc en forma de quelato tuvo efecto sobre el crecimiento de ramas en longitud, de acuerdo con lo reportado por Molina (2002) quien afirma que el zinc quelatado es una ventaja en la nutrición porque facilita la penetración iónica a través de la cutícula foliar cargada negativamente, sin interferencia en la absorción por efecto de repulsión a atracción de cargas eléctricas.

Los quelatos en comparación con las sales, como el sulfato de Zn, pueden ser absorbidos y traslocados más rápidamente para promover el aumento en síntesis de auxinas en yemas apicales de ramas y estimular la elongación y división celular. Esta mayor velocidad de absorción a través de la

Tabla 2. Prueba de comparación múltiple de Tukey para la variable longitud de ramas productivas (cm), en el ensayo de efecto del zinc en gulupa (Passiflora edulis Sims).

\begin{tabular}{|c|c|c|c|c|c|}
$\begin{array}{c}\text { Días después de } \\
\text { aplicación }\end{array}$ & $\begin{array}{c}\text { Testigo } \\
\text { Quelato de Zn } \\
\left(3 \mathrm{~kg} \mathrm{ha}^{-1}\right)\end{array}$ & $\begin{array}{c}\text { Quelato de Zn } \\
\left(6 \mathrm{~kg} \mathrm{ha}^{-1}\right)\end{array}$ & $\begin{array}{c}\text { Quelato de Zn } \\
\left(9 \mathrm{~kg} \mathrm{ha}^{-1}\right)\end{array}$ & $\begin{array}{c}\text { Sulfato de Zn } \\
\left(6 \mathrm{~kg} \mathrm{ha}^{-1}\right)\end{array}$ \\
\hline 0 & $120,0 \mathrm{a}$ & $116,3 \mathrm{a}$ & $118,1 \mathrm{a}$ & $120.0 \mathrm{a}$ & $123,7 \mathrm{a}$ \\
\hline 15 & $130,0 \mathrm{a}$ & $130,2 \mathrm{a}$ & $130,1 \mathrm{a}$ & $130,7 \mathrm{a}$ & $131,2 \mathrm{a}$ \\
\hline 30 & $135,4 \mathrm{a}$ & $140.0 \mathrm{a}$ & $137,7 \mathrm{a}$ & $137,1 \mathrm{a}$ & $134,1 \mathrm{a}$ \\
\hline 45 & $138,7 \mathrm{~b}$ & $173,7 \mathrm{a}$ & $172,1 \mathrm{a}$ & $175,3 \mathrm{a}$ & $133,7 \mathrm{~b}$ \\
\hline 60 & $146,9 \mathrm{~b}$ & $187,3 \mathrm{a}$ & $186,7 \mathrm{a}$ & $187,9 \mathrm{a}$ & $148,2 \mathrm{~b}$ \\
\hline 75 & $154,7 \mathrm{~b}$ & $204,2 \mathrm{a}$ & $199,9 \mathrm{a}$ & $208,4 \mathrm{a}$ & $148,2 \mathrm{~b}$ \\
\hline 90 & $163,7 \mathrm{~b}$ & $214,3 \mathrm{a}$ & $211,4 \mathrm{a}$ & $217,3 \mathrm{a}$ & $156,0 \mathrm{~b}$ \\
\hline 105 & $172,1 \mathrm{~b}$ & $224,5 \mathrm{a}$ & $221,2 \mathrm{a}$ & $227,8 \mathrm{a}$ & $162,2 \mathrm{~b}$ \\
\hline
\end{tabular}

Promedios con letras distintas, en cada día de aplicación, indican diferencia significativa según la prueba de Tukey $(P \leq 0,01)$. 
cutícula constituye una ventaja con relación a sulfato de zinc aplicado al suelo porque no hay riesgo de pérdida del nutrimento por lixiviación y procesos de antagonismo con otros elementos. Además la aspersión al follaje de elementos menores en frutales es un método de suministro más rápido y efectivo que la aplicación al suelo (Rodríguez, 1989).

Vargas-Piedra y Arreloa-Ávila (2008) recomiendan que la fertilización foliar con $\mathrm{Zn}$ se realice cubriendo completamente las partes aéreas de la planta hasta llegar al punto de goteo o región inferior del dosel. Una vez absorbidos por la hoja, el $\mathrm{N}, \mathrm{P}, \mathrm{K}$ y Na se mueven libremente en el floema por todas las estructuras de la planta incluyendo raíces. Perea-Portillo et al. (2010) concluyen que en el cultivo de nogal pecanero (Carya illinoensis) cuando se aplica $\mathrm{Zn}$ foliarmente, se prevé y corrige cualquier deficiencia que presente el árbol, pero si es aplicado edáficamente la respuesta puede tardar algunos años.

La absorción de Zn por las hojas en el cultivo de nogal pecanero es del orden del $1 \%$ de lo asperjado en hojas jóvenes, debido a que la cutícula de la hoja aún no se encuentra suberizada, lo que facilita la penetración y absorción de nutrimentos. Una vez que la cutícula de la hoja se ha suberizado, la absorción del zinc asperjado es solamente de $0,1 \%$ (Favela et al., 2000).

Marschner (2002) asegura que aunque la disponibilidad de $Z n$ en el suelo sea adecuada, su movilidad en la planta es media, por lo tanto el suministro a zonas de síntesis de auxinas como yemas apicales de ramas puede ser afectado, ya que se acumula preferentemente en tejidos radicales.

La aplicación edáfica de Zn fue superada por las aplicaciones foliares, pues aunque el pH del suelo era ácido $(5,25)$ y el contenido de zinc era alto, se presentó la lixiviación del elemento debido a la época lluviosa en la cual se llevó a cabo el experimento y al tipo de suelo en el cual se en- contraban sembradas las plantas (franco arenoso con $56 \%$ de arena). Esta situación es reafirmada por Navarro (2003) quien asegura que en suelos arenosos los riegos y las lluvias penetran fácilmente en ellos realizando un intenso lavado del elemento en el perfil del suelo.

$\mathrm{Al}$ aplicar $\mathrm{Zn}$ edáficamente, este puede reaccionar con hidróxidos y carbonatos en suelos alcalinos y calcáreos, formando compuestos de baja solubilidad, limitando la disponibilidad de este nutriente para las plantas (Núñez-Moreno et al., 2009). Sin embargo, las aplicaciones edáficas con $Z n$ han resultado efectivas en suelos ácidos en el sureste de Estados Unidos, pero son menos efectivas para suelos alcalinos y particularmente en suelos calcáreos (Wood, 2007).

Para las condiciones de la zona de Granada (Cundinamarca), se recomienda, por consiguiente, aplicar $3 \mathrm{~kg} \mathrm{ha}^{-1}$ de $\mathrm{Zn}$ foliarmente en forma de quelato, con tres aplicaciones quincenales como mínimo para observar el efecto del elemento sobre las plantas porque se aumenta el crecimiento de las ramas productivas en longitud, aunque como lo anotan Favela et al. (2000), para establecer el número adecuado de aplicaciones se deben realizar análisis del contenido de zinc en el tejido foliar para establecer intervalos de deficiencia, suficiencia y exceso, y de esta forma evitar desbalances con manganeso y cobre, lo cual conlleva a retrasos en la floración y senescencia al encontrarse elevadas concentraciones de AIA.

\section{Número de brotes productivos}

Para el número de brotes no se observaron diferencias estadísticas entre tratamientos, teniendo un rango de valores promedio entre tratamientos de 1,43 a 2,04 brotes por mes, por tanto no se observó efecto de la aplicación de zinc sobre esta variable debido posiblemente a que predominaron los procesos de elongación celular con respecto a los de división celular, aumentando la distancia entrenudos, lo cual se vio reflejado en la variable longitud de ramas productivas. De 
acuerdo con Broadley et al. (2007), la deficiencia severa de zinc induce entrenudos cortos, epinastia y reducción en el área foliar debido a la deficiencia de auxina.

Lo anterior es corroborado por García et al. (2006), quienes afirman que uno de los efectos primarios del tratamiento con auxina implica cambios en el metabolismo celular que producen un rápido bombeo de protones a través de la membrana celular. La acidificación resultante de la pared conduce a la hidrólisis de los puentes que unen distintas moléculas dentro de la pared y consecuentemente, a la elongación celular forzada por la presión de turgencia.

Probablemente no se observó respuesta de las plantas en el número de brotes productivos debido a que la mayor síntesis de auxinas por efecto de la aplicación de $Z n$ fue en las partes apicales de las ramas productivas incrementando su crecimiento, de acuerdo con Salisbury y Ross (1994). Como el AIA es sintetizado en el ápice de la planta, especialmente en hojas jóvenes, y muestra un transporte polar, se ha postulado que la auxina causa la represión de los brotes laterales al moverse basípetamente (Srivastava, 2002).

Aunque el efecto observado por la aplicación de zinc fue únicamente en la longitud de ramas productivas, se puede estimular el crecimiento en número y longitud de nuevos brotes al realizar una poda de estas por medio de un pinch en las puntas, ya que de acuerdo con Taiz y Zeiger (2006) la yema apical ejerce una influencia inhibitoria (dominancia apical) sobre las yemas laterales, impidiendo o retardando su desarrollo, por tanto al podar se incrementarán las ramificaciones.

En un experimento llevado a cabo por Arrieche y Ramírez (1999) para determinar la absorción de Zn y su relación con la materia seca del maíz y el Zn del suelo, se encontró respuesta a la aplicación de 5 y $10 \mathrm{mg} \mathrm{kg}^{-1}$ de $\mathrm{Zn}$ al suelo. Cuando la dosis de zinc se incrementó a $15 \mathrm{mg} \mathrm{kg}^{-1}$ de $\mathrm{Zn}$, no se encontró respuesta. El incremento de la materia seca fue de 2,95 g/planta con la aplicación de Zn de $5 \mathrm{mg} \mathrm{kg}^{-1}$ de suelo, lo que significó un aumento del $45,5 \%$ con respecto al testigo. Con $10 \mathrm{mg}$ se consiguió un incremento de 0,44 $\mathrm{g} /$ planta de materia seca, es decir $4,7 \%$. Con un incremento a $15 \mathrm{mg}$ se produjo una disminución de la materia seca en $16,5 \%$. Este comportamiento muestra una alta respuesta inicial a la aplicación de zinc al suelo y una máxima respuesta alrededor de $10 \mathrm{mg} \mathrm{kg}^{-1}$ de $\mathrm{Zn}$ al suelo. Adicionalmente, la absorción de N, P, K y Ca mostró en general un incremento a medida que la dosis de zinc aplicada fue mayor.

\section{CONCLUSIONES}

La fertilización foliar utilizando como fuente quelato de zinc en una dosis de $3 \mathrm{~kg} \mathrm{ha}^{-1}$ de Zn mostró el mayor efecto sobre longitud de ramas productivas en el cultivo de gulupa para la zona de Granada (Cundinamarca), aumentando la elongación y distancia entrenudos debido a la probable síntesis del aminoácido triptófano como precursor de auxinas.

La fertilización edáfica con sulfato de $\mathrm{Zn}$ no presentó resultados relevantes sobre las variables evaluadas debido al alto porcentaje de arena en la parcela donde se encontraba establecido el cultivo y a la alta precipitación lo que conllevó a la lixiviación del elemento en el perfil del suelo.

No se observó respuesta de las plantas a la aplicación de Zn para la variable número de brotes productivos, debido a que primaron los procesos de elongación celular evidenciados en el aumento de la distancia entrenudos, lo cual probablemente esté relacionado con la síntesis de auxinas. 


\section{REFERENCIAS BIBLIOGRÁFICAS}

Arrieche, I. y R. Ramírez. 1999. Absorción de zinc y su relación con la materia seca del maíz y el zinc del suelo. Agron. Trop. 49 (3), 261-273.

Broadley, M.R, P.J. White, J.P. Hammond, I. Zelko y A. Lux. 2007. Zinc in plants. New Phytologist 173, 677-702.

Cakmak, I. y H. Marschner. 1988. Enhanced superoxide radical production in roots of zinc- deficient plants. Exp. Bot 39, 1449-1460.

Espinel, C., H. Martínez y Y. Peña. 2005. La cadena de los frutales de exportación en Colombia: una mirada global de su estructura y dinámica (1191-2005). Documento de trabajo número 67. Observatorio Agrocadenas Colombia. Ministerio de Agricultura y Desarrollo Rural, Bogotá. pp. 37-39.

Fassbender, H.W. y E. Bornemisza. 1987. Química de suelos con énfasis en América Latina. Instituto Interamericano de Cooperación para la Agricultura (IICA), San José.

Favela, E., J.I. Cortés, G. Alcántar, J.D. Etchevers, G.A. Baca y J. Rodríguez. 2000. Aspersiones foliares de zinc en nogal pecanero en suelos alcalinos. Terra Latinoamericana 18(3), 239-245.

Fischer G., F. Casierra-Posada y W. Piedrahíta. 2009. Ecofisiología de las especies pasifloráceas cultivadas en Colombia. pp. 45-68. En: Miranda, D., G. Fischer, C. Carranza, S. Magnitskyi, F. Casierra, W. Piedrahíta y L.E. Flórez (eds.). Cultivo, poscosecha y comercialización de las pasifloráceas en Colombia: maracuyá, granadilla, gulupa y curuba. Sociedad Colombiana de Ciencias Hortícolas. Bogotá.

García, F.., J. Roselló y M.P. Santamarina. 2006. Introducción al funcionamiento de las plantas. Editorial de la Universidad Politécnica de Valencia, Valencia, España.

Gil, F. 1995. Elementos de la fisiología vegetal. Ediciones Mundi-Prensa, Madrid.

Hanafy-Ahmed, A.H., M.K. Khalil, A.M. Abd EIRahman y N.A.M. Hamed. 2012. Effect of zinc, tryptophan and indole acetic acid on growth, yield and chemical composition of Valencia orange trees. J. Appl. Sci. Res. 8(2), 901-914.
Kirkby, E. y V. Römheld. 2007. Micronutrientes en la fisiología de las plantas: funciones, absorción y movilidad. The International Fertilizer Society, New York, N.Y.

Klein, R.M., E.M. Caputo y B.A. Witterholt. 1962. The role of zinc in the growth of plant tissue cultures. Amer. J. Bot. 49(4), 323-327.

Knight, R.J. y J.W. Sauls. 2005. The passion fruit. IFAS Extension. Horticultural Sciences Department, University of Florida, Gainesville, FL.

Lasat, M.M. y L.V. Kochian. 2000. Physiology of Zn hyperaccumulation in Thlaspi caerulescens. Phytoremediation of contaminated soil and water. CRC Press, Boca Raton, FL.

Marschner, H. 2002. Mineral nutrition of higher plants. Academic Press, London.

Molina, E. 2002. Fertilización foliar de cultivos frutícolas. pp. 85-104. En: Meléndez, G. y E. Molina (eds.). Memorias Seminario Fertilización Foliar: Principios y Aplicaciones. Laboratorio de Suelos CIA-UCR/ACCS, San José.

Nakasone, H. y R.E. Paull. 1998. Tropical fruits. CAB Internatinal. Wallington, UK.

Navarro, G. 2003. Química agrícola: el suelo y los elementos químicos esenciales para la vida vegetal. Ediciones Mundi-Prensa, Madrid.

Núñez-Moreno, H., A. Walworth, P. Pond y M. Kilby. 2009. Soil zinc fertilization of "Wichita" pecan trees growing under alkaline soil conditions. HortScience 44, 1736-1740.

Perea-Portillo, E., D.L. Ojeda-Barrios, O.A. HernándezRodríguez, D.J. Escudero-Almanza, J.J. MartínezTéllez y G.R. López-Ochoa. 2010. El zinc como promotor de crecimiento y fructificación en el nogal pecanero. Revista Tecnociencia Chihuahua 4(2), 64-71.

Ratto S.E., Fatta N. y M. Lamas. 1991. Análisis foliar en maíz de cultivo. II: Microelementos. Rev. Fac. Agron. (La Plata) 12(1), 31-38. 
Ratto, S.E. y F.H. Miguez. 2006. Zinc en el cultivo de maíz, deficiencia de oportunidad. Informaciones Agronómicas 63, 8-15.

Ríos, R. y F. Corella. 1999. Manejo de la nutrición y fertilización del mango en Costa Rica. pp. 277-290. Memorias XI Congreso Nacional Agronómico/III Congreso Nacional de Suelos, San José de Costa Rica.

Rodríguez, S.F. 1989. Fertilizantes, nutrición vegetal. AGT Editor S.A, México.

Rout, G.R. y P. Das. 2003. Effect of metal toxicity on plant growth and metabolism: I. Zinc. Agronomie 23, 3-11.

Salisbury, F. y C. Ross. 1994. Fisiología vegetal. Grupo Editorial Iberoamericana, México

Sattelmacher, B. 2001. The apoplast and its significance for plant mineral nutrition. New Phytologist 149, 167-192.

Sekimoto, H., M. Hoshi., T. Nomura y T. Yokota. 1997. Zinc deficiency affects the levels of endogenous gibberellins in Zea mays L. Plant Cell Physiol. 38(9), 1087-1090.

Sikkema, A. 2010. Zinc switches found in plants. Proceedings of the National Academy of Sciences
(PNAS). En: http: www.wur.nl/UK; consulta: 11 de enero de 2012.

Srivastava, L. 2002. Plant growth and development: hormones and environment. Academic Press, San Diego, CA.

Taiz, L. y E. Zeiger E. 2006. Plant physiology. $4^{\text {th }}$ ed. Sinauer Associates, Sunderland, MA.

Takatsuji, H. 1998. Zinc-finger transcription factors in plants. Cell Mol. Life Sci. 54, 582-596.

Vargas-Piedra, G. y J.G. Arreola-Ávila. 2008. Respuesta del nogal pecanero (Carya illinoensis $\mathrm{K}$. Koch) a las aplicaciones foliares de nutrimentos. Rev. Chapingo Ser. Zonas Áridas 7, 7-14.

Wenkam, N.S. 1990. Food of Hawaii and the Pacific Basin: Fruits and fruit products (Raw, processed and prepared). Vol 4. Composition Res. Ext. Serv. No. 110. Hawaii Agr. Exp. Sta., College Trop. Agr. Human Resources, University of Hawaii, Honolulu.

White, P.J. 2001. The pathways of calcium movement to the xylem. J. Exp Bot 52, 891-899.

Wood, B. 2007. Correction of zinc deficiency in pecan by soil banding. HortScience 42, 1554-1558. 